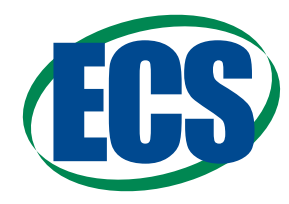

\title{
Review-Recent Advances in Block-Copolymer Nanostructured Subwavelength Antireflective Surfaces
}

\author{
Sajjad Husain Mir, ${ }^{1,2, z}$ Gaulthier Rydzek, ${ }^{1,2}$ Larry Akio Nagahara,,* Ajit Khosla, ${ }^{4, *}$ \\ and Parvaneh Mokarian-Tabari $\oplus^{1,2, \mathrm{z}}$ \\ ${ }^{1}$ Advanced Material and BioEngineering Research Centre (AMBER), Trinity College Dublin, The University of Dublin, \\ Ireland \\ ${ }^{2}$ School of Chemistry, Trinity College Dublin, The University of Dublin, Dublin 2, Ireland \\ ${ }^{3}$ Department of Mechanical System Science, Graduate School of Science and Engineering, Yamagata University, \\ Yonezawa, Yamagata 992-8510, Japan \\ ${ }^{4}$ Department of Chemical and Biomolecular Engineering, Whiting School of Engineering, Johns Hopkins University, \\ 3400 North Charles Street, Baltimore, Maryland 21218, USA
}

\begin{abstract}
Nanostructured Anti-Reflective (AR) surfaces have attracted a focused attention during the last few years and offer an alternative to AR coatings. Recent nanopatterning approaches have allowed fabrication of bioinspired nanostructured surfaces with unprecedented broadband and omnidirectional AR properties. However, nanofabrication methods face major challenges for reaching industrial maturity including high capital expenditure cost, scalability, reliability and adaptability of the technologies. Block copolymer (BCP) films provide one way to overcome some of these limitations by offering scalable and versatile masks to fabricate well-defined, uniform and tunable nanostructures on a variety of substrates at a modest price. This article aims at highlighting recent efforts for assembling such AR nanostructured surfaces with BCP films and the challenges yet to tackle prior to commercialization of the technology.

(C) The Author(s) 2019. Published by ECS. This is an open access article distributed under the terms of the Creative Commons Attribution 4.0 License (CC BY, http://creativecommons.org/licenses/by/4.0/), which permits unrestricted reuse of the work in any medium, provided the original work is properly cited. [DOI: $10.1149 / 2.0022003 \mathrm{JES}$ ]

(cc) BY
\end{abstract}

Manuscript submitted January 7, 2019; revised manuscript received July 17, 2019. Published September 20, 2019. This paper is part of the JES Focus Issue on Sensor Reviews.

Reflection of light is one of the critical issues limiting the efficiency of devices in several application fields, including optics, photovoltaics and detectors. ${ }^{1-6}$ As early as 1879 , the issue of reflectivity of optical substrates was a well studied. Lord Rayleigh proposed that reflection of light could be reduced by smoothing the refractive index transition between the substrate and its environment. ${ }^{7}$ Following this concept, basic antireflective (AR) coatings were developed (Figure 1a), and later refined to utilize destructive interference of refracted light caused by multilayer dielectric coatings, alternating high and low refractive indexes. ${ }^{8-10}$ However, modern optoelectronic devices place new demands on the optics market that cannot be addressed at a reasonable cost by such multilayer dielectric coatings. Indeed, current optoelectronic devices require (1) broadband AR over large areas; (2) insensitivity to the incident angle (omnidirectional); and (3) chemical and mechanical robustness for end-use application.

Such properties are often found in the natural world. ${ }^{11}$ For instance, a close inspection of the cornea of night-flying moths reveals an ordered array of conical protuberances, typically of $200 \mathrm{~nm}$ height and spacing. ${ }^{12}$ Biomimicry of these surface nanostructures became a major research avenue in the pursuit of AR, by graded refractive index. (Figure 1b). As early as 1973, moth-eye coatings applied to glass gave a reduction of the reflection of "white light" (a broad spectrum of visible light) from $5.5 \%$ to $0.2 \% .^{13}$ These promising results triggered a surge in development of similar AR coatings including, but not restricted to, oblique incidence thin film deposition methods, ${ }^{1}$ replicated polymer structures, ${ }^{14,15}$ nanoporous polymers ${ }^{7,16}$ and carbon nanotube arrays. ${ }^{17}$

In recent years, improvement of micro/nanofabrication tools and methods have enabled the nanostructuring of substrate surfaces directly, creating robust $\mathrm{AR}$ surfaces without coatings (Figures $1 \mathrm{c}$, 1d). ${ }^{18-22}$ This article aims to highlight recent efforts for fabrication of such AR nanostructured surfaces and the challenges remaining that should be addressed prior to commercialization.

\section{Current Status}

Overview.-Direct nanostructuring of the substrate surface offers several advantages over coatings in the fields of optics, eliminating intermediate layers between the substrate and its environment reduces the risk of releasing hazardous materials, and enables better control over the substrate/environment interaction. Several strategies have thus been developed to fabricate a nanostructure on the surface of silicon, fused silica, sapphire and PDMS. These include direct laser writing, ${ }^{24}$ direct reactive ion etching, ${ }^{25}$ chemical etching, ${ }^{26}$ electrochemical oxidation ${ }^{27}$ and imprinting. ${ }^{28,29}$ However, the lack of scalability, adaptability to different substrate materials and geometries (e.g. curvature) and high capital/operating cost of such fabrication methods are a major technological hurdle for exploitation. Some of these challenges can be overcome by using lithographic approaches, introducing a process step of masking the substrates with a nanoscale pattern, to be transferred to the surface. Therefore, the preparation

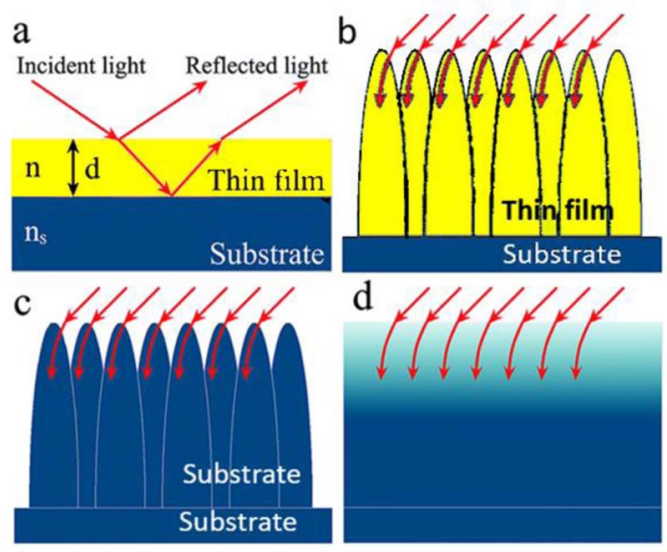

Figure 1. Schematic depiction of (a) interaction of light through one layer toward substrate, (b) light interaction with a nanopatterned coating and (c) light interaction with a nanopatterned substrate. (d) Illustration of refractive index change with respect to (c). ${ }^{23}$ Adapted with permission from Ref. 23, Copyright 2015, Royal Society of Chemistry. 
Table I. Reported methods for fabricating AR surfaces using a mask.

\begin{tabular}{|c|c|c|c|}
\hline Ref & Mask type and etching approach & $\begin{array}{l}\text { Substrate(s) and structure dimensions } \\
\text { demonstrated }\end{array}$ & Advantages/drawbacks \\
\hline $2,34-37$ & $\begin{array}{l}\text { Mask: Metal microdomains either sputtered } \\
\text { or thermally dewetted } \\
\text { Etch: ICP dry etch }\end{array}$ & $\begin{array}{l}\text { Substrates: Glass, germanium, sapphire and } \\
\text { teflon } \\
\text { Nanopillars and nanocones up to } 192 \mathrm{~nm} \\
\text { diameter and } 350 \mathrm{~nm} \text { height }\end{array}$ & $\begin{array}{l}\text { Size-tunable and excellent contrast etch. Poor } \\
\text { size distribution of the nanostructures. Special } \\
\text { equipment required. }\end{array}$ \\
\hline 38,39 & $\begin{array}{l}\text { Mask: Colloidal monolayer } \\
\text { Etch: Plasma etching }\end{array}$ & $\begin{array}{l}\text { Substrate: Silicon } \\
\text { Nanowires up to } 440 \mathrm{~nm} \text { diameter and } 8.9 \mu \mathrm{m} \\
\text { height }\end{array}$ & $\begin{array}{l}\text { Inexpensive, fast and simple. Excellent aspect } \\
\text { ratio on silicon. Compatible with rough } \\
\text { surface topographies, } \\
\text { Etch contrast limited on glass and sapphire. } \\
\text { Density of nanostructures limited }\end{array}$ \\
\hline 40 & $\begin{array}{l}\text { Mask: Colloid monolayer }+ \text { metal } \\
\text { evaporation } \\
\text { Etch: Metal assisted chemical etching }\end{array}$ & $\begin{array}{l}\text { Substrate: Silicon } \\
\text { Nanowires up to } 475 \mathrm{~nm} \text { diameter and } 12 \mu \mathrm{m} \\
\text { height }\end{array}$ & $\begin{array}{l}\text { Simple and scalable. Excellent aspect ratio on } \\
\text { silicon. } \\
\text { Density of nanostructures limited. Special } \\
\text { equipment required. }\end{array}$ \\
\hline 41-44, & $\begin{array}{l}\text { Mask: Self-assembled block-copolymer film } \\
\text { Etch: ICP or plasma etching }\end{array}$ & $\begin{array}{l}\text { Substrates: Silicon, glass, GaN } \\
\text { Nanopillars up to } 110 \mathrm{~nm} \text { diameter and } 1150 \mathrm{~nm} \\
\text { height }\end{array}$ & $\begin{array}{l}\text { Low cost, scalable, tunable nanostructures, high } \\
\text { aspect ratio, adaptable on objects with } \\
\text { complex shape (solution based) } \\
\text { Etch contrast limited }\end{array}$ \\
\hline
\end{tabular}

of such masks could be considered as a critical factor for preparing high-performance AR surfaces and we anticipate its successful industrial applications. These masks should ideally achieve, at reasonable cost and with scalable processes: (i) uniformity and versatility of the pattern, (ii) tolerance to the substrate size and geometry (iii) a high contrast pattern transfer (etch) for a range of substrates. Accordingly, several lithographic approaches can be considered viable for fabricating nanostructures on a wide variety of materials including silicon, glass, sapphire and $\mathrm{GaN}^{30-33}$ (Table I).

Block-copolymer masks for AR surfaces.-Block-copolymer (BCP) films deposited by solution-processing techniques ${ }^{41}$ can selfassemble into microphase-separated arrays, providing well-defined periodic nanostructured surfaces over large areas and with a remarkable compatibility with both the substrate material and geometry. ${ }^{46,47}$ The characteristics of each block composing the BCP, including their Flory-Huggins interaction parameter $(\chi)$, their degree of polymerization $(\mathrm{N})$, and their volume fraction $\left(f_{\mathrm{A}}\right)$, enable a range of microphase separation regimes that can be observed both theoretically and experimentally. ${ }^{49}$ Segregation of the different blocks composing the $\mathrm{BCP}$ into well-controlled microdomains may be influenced via a few parameters including the BCP-substrate interaction, the film thickness, the temperature and the solvent (Figure 2a). ${ }^{49}$ In practice, different strategies are used to induce and control the microphase separation and self-assembly, including thermal annealing, ${ }^{50}$ solvent vapor annealing (SVA) ${ }^{51}$ solvothermal annealing, ${ }^{52}$ microwave-assisted SVA, ${ }^{53-55}$ chemical substrate modification and patterning, ${ }^{56}$ graphoepitaxy, ${ }^{57}$ electrical/magnetic field alignment, ${ }^{58}$ and shear alignment. ${ }^{59}$ While each technique has merits and demerits, ${ }^{60-62}$ the wide variety of strategies contributes to the versatility of the BCP pattern as a mask. Depending on the substrate to be etched, microphase separated BCP films can be further treated to generate either polymer or metal-oxide masks with the desirable etch contrast property (Figure $2 b$ routes 1 and 2 ).

Paivanranta et al. ${ }^{42}$ have used BCPs to create antireflective nanostructures on fused silica, and were able to reduce the reflectivity of fused silica to below $1 \%$. Thermal annealing of a film of lamellar polystyrene-block-poly(methyl methacrylate) (PS- $b$-PMMA, PS:PMMA 1:1), on a chromium coated fused silica formed PMMA microdomains oriented perpendicular to the substrate. Selective removal of the PMMA block yielded a PS pattern, which was used as an intermediate mask to etch the Cr layer, creating the final etch mask to dry etchthe fused silica.
Using the same BCP but a different volume fraction (PS:PMMA $\sim 7: 3$ ), Rahman et al. ${ }^{43}$ obtained 25-nm-diameter PMMA cylindrical microdomains within a PS matrix, hexagonally arranged with a separation of $40 \mathrm{~nm}$ to $67 \mathrm{~nm}$ depending on the BCP molecular weight. Impregnation of PMMA domains with alumina using sequential in-

\section{a}
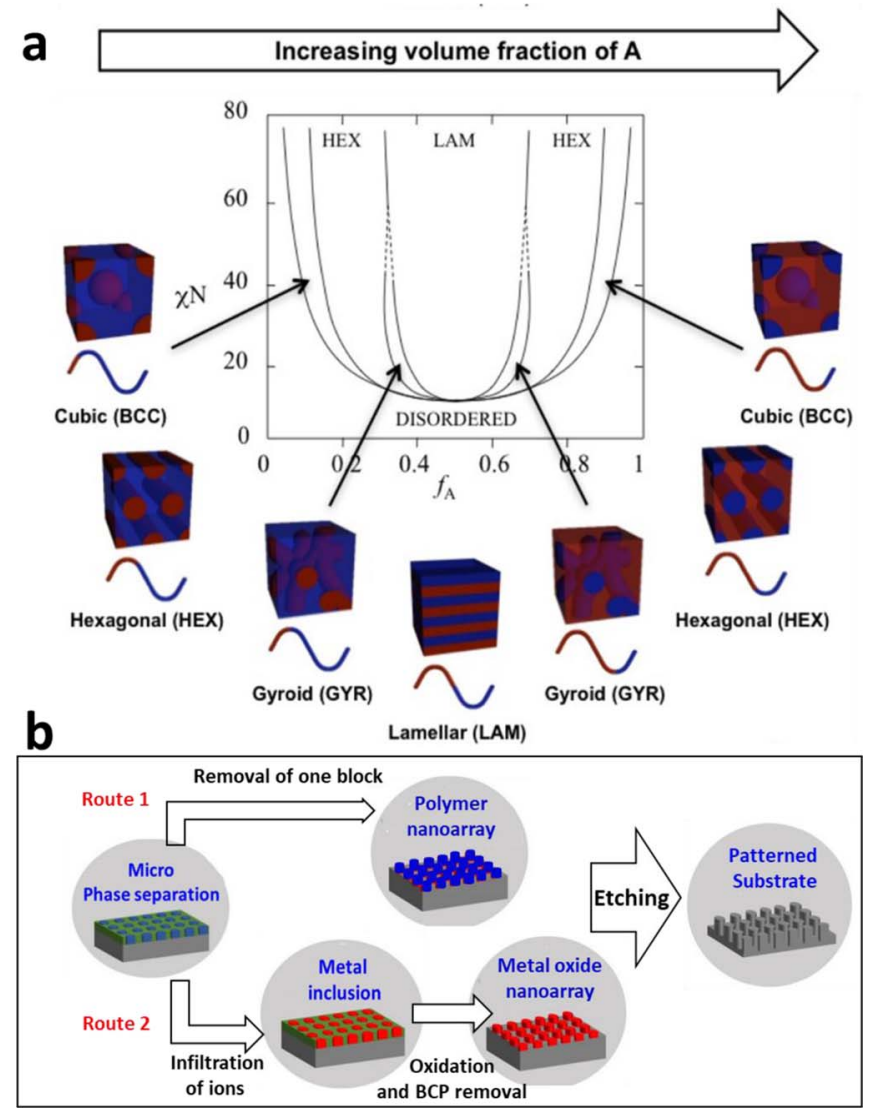

Figure 2. a) Theoretical phase diagram and evolution of corresponding morphologies in BCP. Reproduced with permission from Ref. 49, Copyright 2006, American Chemical Society. b) Different strategies that have been developed to use BCP microphase separated films as masks for lithography. 
(a) Ordered Si nanopillars obtained by sequential infiltration synthesis of Aluminium oxide within PS- $b$-PMAA ${ }^{43}$
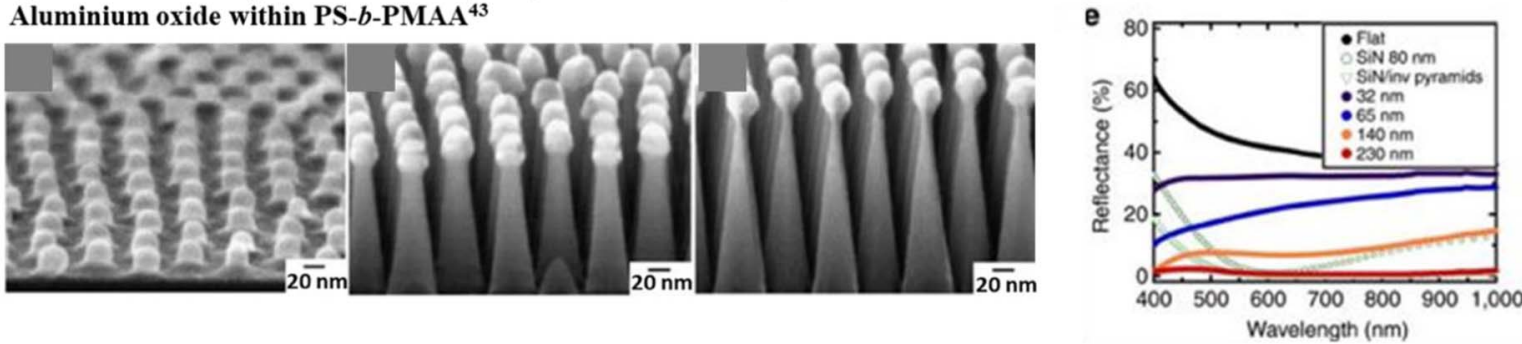

(b) High aspect ratio Si nanopillars obtained by spin cast infiltration of iron oxide in high molecular weight PS- $b-\mathbf{P 2 V P}^{41}$
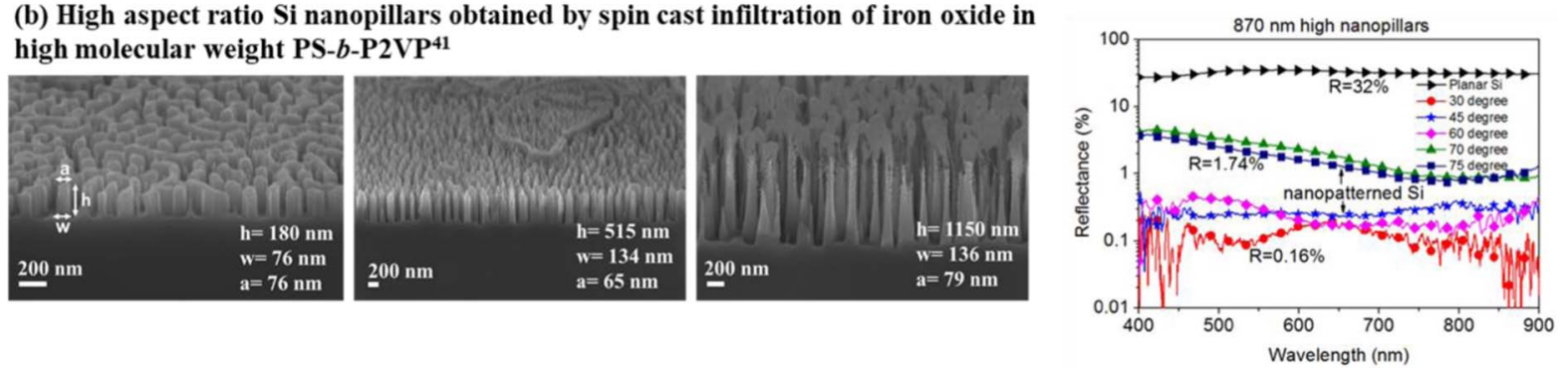

Figure 3. a) Silicon nanopillars with tunable aspect ratio and their AR performances, assembled from metal oxide nanoarray masks via microphase-separated BCP films. Adapted with permission from Ref. 43 (Copyright 2014, Nature Publication Group), and b) from Ref. 41 (Copyright 2017, American Chemical Society).

filtration synthesis, followed by oxygen plasma removal of the $\mathrm{BCP}$ yielded an aluminum oxide mask that was used to dry etch the silicon substrate. This process resulted in silicon nanopillars, with a varying aspect ratio that could be tuned by changing the etching time (Figure 3a). The obtained nanostructured surface mimics the moth eye structure, reducing surface reflectance from $35 \%$ (flat surface) to $<1 \%$ in the visible range and at incident angles below 60 degrees. The nanostructured silicon, used in a solar cell, significantly enhanced the cell performance. However, at higher angles of incidence, the reflection increased dramatically, to about $40 \%$. This is mainly attributed to relatively small periodicity of the nanostructure obtained from the block copolymer mask, in comparison to the wavelength of the visible light, and the height of the nanopillars. Synthesizing high molecular weight block copolymers (to enable masks with higher periodicity), that still have reliable phase separation, is the main fundamental challenge for wider application of this technique. ${ }^{63}$

Recently, Mokarian et al. ${ }^{41}$ "trapped" a non-equilibrium structure in ultra-high molecular weight BCP with domains large enough to interact with visible light. A large poly(styrene- $b$-2-vinylpyridine) (PS- $b$-P2VP, $793 \mathrm{Kg}_{\mathrm{mol}}{ }^{-1}$, PS:P2VP 1.24:1) BCP was used to obtain periodic hexagonal P2VP microdomains of $115 \mathrm{~nm}$ with spacing greater than $160 \mathrm{~nm}$ (Figure 3b). The pattern is thought to be a kinetically metastable phase. Infiltration of P2VP microdomains with iron ions and removal of the PS by $\mathrm{UV}_{-} \mathrm{O}_{3}$ resulted in an array of ironoxide dots, used as a mask for etching. Considering the large molecular weight of the $\mathrm{BCP}$, achieving microphase separation is promising for applications requiring $\mathrm{AR}$ in the visible spectrum. Indeed, the large size and spacing of P2VP microdomains, as well as the high etch contrast of the iron oxide mask enabled fabrication of large and high aspect ratio nanopillars on various substrates. Omnidirectional and broadband reduction of reflectivity of silicon at two orders of magnitude (reflectivity below $0.16 \%$ ) was achieved. Furthermore, the reflection remained low (around $1.7 \%$ ) at higher angle of incident, up to $75^{\circ}$ in the visible light range. This is attributed to to the height of nanopillars $(600-1100 \mathrm{~nm})$.

\section{Discussion, Challenges and Opportunites}

For an efficient broadband and omnidirectional AR effect in the visible range (400-700 nm), surfaces need to be patterned with high aspect ratio nanopillars and a periodicity larger than $100 \mathrm{~nm}$ (typically $\frac{1}{4} \lambda$ of the smallest wavelength of incident light). Achieving such dimensions using a BCP-derived mask requires use of large molecular weight BCPs. This is challenging for several reasons: ${ }^{63}$

(a) Synthesizing high molecular weight BCPs above $500,000 \mathrm{~kg} / \mathrm{mol}$ faces significant challenges for both the molecular mass monodispersity of the BCP and the reproducibility of synthesis. It typically requires minimizing the level of impurities in the synthesis reactor, at low temperature. The obtained polymers can be poorly soluble, limiting the homogeneity of the resulting $\mathrm{BCP}$ films

(b) With a few exceptions, BCPs do not easily phase separate above $100 \mathrm{~nm}$ microdomains. This issue arises from significant kinetic penalties and larger chain entanglement in high molecular weight polymers.

(c) Obtaining high aspect ratio nanopillars (greater than 4) from large microdomains (100 $\mathrm{nm}$ or above) requires etching the substrate more than $400 \mathrm{~nm}$ deep. The current etch resistance and selectivity of masks obtained from BCP patterns, although sufficient for etching high aspect-ratio structures in silicon, ${ }^{41,43,64}$ need improvement for reaching similar capabilities on other substrates such as glass ${ }^{41,65}$ or sapphire. The amorphous nature of glass makes it more difficult to etch.

To overcome these challenges, new large BCPs may be designed with blocks presenting large Flory-Huggins parameters in order to facilitate their microphase separation. ${ }^{66}$ Combining lower molecular weight $\mathrm{BCP}$ with another component such as inorganic blocks or metals, leading to a hybrid system, offers an alternative solution for generating resistant and large mask features. ${ }^{67-69}$ With these BCPs available to form masks, reduced reflection for a range of substrates in the visible spectrum may be within reach. Should AR in the near infrared (NIR) spectrum be required, it will be critical to further advance this development, as patterns with high periodicity (above $100 \mathrm{~nm}$ ) will be needed.

Beside the challenges associated with assembling large mask features, fabrication methods using BCPs have been limited in industrial use due to a tendency to find large defect densities in the resulting surface nanostructure, affecting the performance and consistency of the component in its intended device. Indeed, dewetting or poorly microphase-separated areas in BCP films will ultimately translate into lack of homogeneity for the pillar/nanostructure density after etching the substrate. Solving these issues requires a better control over 
environmental parameters that influence the microphase-separation. Specifically, the annealing conditions and the film processing methods could be optimized with a better understanding of the relationship between thermodynamic and kinetic pathways for BCP microphaseseparation. Studying this relationship would require the development of more advanced equipment capable to observe the separation in-situ. While selectively infiltrating BCP blocks with metallic ions successfully forms a metal-oxide masks with good etch contrast (Figure 2b), the fundamental mechanism driving this process should be better understood, to avoid size polydispersity of the metal-oxide domains. Finally, some industrial requirements are still to be validated, such as to confirm the durability and robustness of the nanostructured AR surfaces and their environmental impact, in comparison to benchmark of AR coatings.

Despite the challenges that remain before entering the market, there are many reasons to be optimistic for the future of nanostructured AR surfaces derived from microphase-separated BCPs. This approach has the potential to be the most viable manufacturing method for commercialisation, in terms of cost efficiency, scalability and adaptability to surfaces of large size and with complex shape. With further development, in addition to AR, this nanostructuring method could also be used to give other functionalities to surfaces, including self-cleaning, antifogging and structural colouring over large areas.

\section{Acknowledgments}

This project has received funding from the European Union's Horizon 2020 research and innovation programme under the Marie Skłodowska-Curie grant agreement No. 713567, and from the European Union's Horizon 2020 research and innovation programme under grant agreement No 760915. This work was also supported by Enterprise Ireland Commercialization Fund under project No. 206727 and by Science Foundation Ireland (SFI) under grant Number 12/RC/2278_P2.

\section{ORCID}

Sajjad Husain Mir (D) https://orcid.org/0000-0001-8416-3891 Gaulthier Rydzek (D) https://orcid.org/0000-0002-2901-3441 Ajit Khosla (D) https://orcid.org/0000-0002-2803-8532

Parvaneh Mokarian-Tabari (i) https://orcid.org/0000-0002-5176-0478

\section{References}

1. J.-Q. Xi, M. F. Schubert, J. K. Kim, E. F. Schubert, M. F. Chen, S.-Y. Lin, W. Liu, and J. A. Smart, Nat. Photonics, 1, 176 (2007).

2. J. W. Leem, Y. Yeh, and J. S. Yu, Optics Express, 20, 4056 (2016).

3. T. Lohmüller, M. Helgert, M. Sundermann, R. Brunner, and J. P. Spatz, Nano Lett. 8, 1429 (2008).

4. Y. M. Song, Y. Xie, V. Malyarchuk, J. Xiao, I. Jung, K.-J. Choi, Z. Liu, H. Park, C. Lu, R.-H. Kim, K. B. Crozier, Y. Huang, and J. A. Rogers, Nature, 497, 95 (2013).

5. K.-H. Jeong, J. Kim, and L. P. Lee, Science, 312, 557 (2006).

6. J.-J. Kim, Y. Lee, H. G. Kim, K.-J. Choi, H.-S. Kweon, S. Park, and K.-H. Jeong, Proc. Natl. Acad. Sci. U.S.A., 109, 18674 (2012).

7. L. Rayleigh, Proc. Lond. Math. Soc., 1, 51 (1879).

8. Y.-F. Huang, S. Chattopadhyay, Y.-J. Jen, C.-Y. Peng, T.-A. Liu, Y.-K. Hsu, C.-L. Pan, H.-C. Lo, C.-H. Hsu, Y.-H. Chang et al., Nat. Nanotechnol., 2, 770 (2007).

9. J. van de Groep, P. Spinelli, and A. Polman, Nano Lett. 15, 4223 (2015).

10. J. A. Hiller, J. D. Mendelsohn, and M. F. Rubner, Nat. Mater., 1, 59 (2002).

11. Z. Han, Z. Jiao, S. Niu, and L. Ren, Prog. Mater. Sci., 103, 1 (2019).

12. C. G. Bernhard, Endeavour, 26, 79 (1967).

13. P. B. Clapham and M. C. Hutley, Nature, 244, 281 (1973).

14. C. David, P. Haberling, M. Schnieper, J. Sochtig, and C. Zschokke, Microelectron. Eng., 61-62, 435 (2002)

15. Kassegne Sam, Kee Moon, Pablo Martín-Ramos, Mohammad Majzoub, Gunay Ózturk, Krishna Desai, Mihir Parikh, Bao Nguyen, Ajit Khosla, and Pedro Chamorro-Posada, "Organic MEMS/NEMS-based high-efficiency 3D ITOless flexible photovoltaic cells." Journal of Micromechanics and Microengineering, 22(11), 115015 (2012).

16. M. Ibn-Elhaj and M. Schadt, Nature, 410, 796 (2001).

17. Z. P. Yang, L. Ci, J. A. Bur, S. Y. Lin, and P. M. Ajayan, Nano Lett. 8, 446 (2008).
18. Y. Kanamori, K. Hane, H. Sai, and H. Yugami, Appl. Phys. Lett., 78, 142 (2001).

19. C. C. Striemer and P. M. Fauchet, Appl. Phys. Lett., 81, 2980 (2002).

20. Y. C. Chang, G. H. Mei, T. W. Chang, T. J. Wang, D. Z. Lin, and C. K. Lee, Nanotechnology, 18, 285303 (2007).

21. W. H. Lowdermilk and D. Milam, Appl. Phys. Lett., 36, 891 (1980).

22. B. Paivanranta, T. Saastamoinen, and M. A. Kuittinen, Nanotechnology, 20, 375301 (2009).

23. J. Caiab and L. Qi, Mater. Horiz., 2, 37 (2015).

24. J. Yang, F. Luo, T. S. Kao, X. Li, G. W. Ho, J. Teng, X. Luo, and M. Hong, Light: Scie. \& App., 3, e185 (2014).

25. S. J. Cho, T. An, J. Y. Kim, J. Sung, and G. Lim, Chem. Commun., 47, 6108 (2011).

26. J. Kim, G. V. Naik, N. K. Emani, U. Guler, and A. Boltasseva, IEEE Jour. of Selected Topics in Quant. Elec., 3, 4601907 (2013).

27. K. Choi, S. H. Park, Y. M. Song, Y. T. Lee, C. K. Hwangbo, H. Yang, and H. S. Lee, Adv Mat., 22, 3713 (2010).

28. Y. Liu, Y. Song, S. Niu, Y. Zhang, Z. Han, and L. Ren, RSC Adv., 6, 108974 (2016).

29. K. Choi, S. H. Park, Y. M. Song, Y. T. Lee, C. K. Hwangbo, H. Yang, and H. S. Lee, Adv. Mater, 22, 3713 (2010).

30. T. Deng, C. T. Chen, C. Honeker, and E. L. Thomas, Polymer, 44, 6549 (2003).

31. D. A. Hajduk, P. E. Harper, S. M. Gruner, C. C. Honeker, G. Kim, E. L. Thomas, and L. J. Fetters, L. Macromolecules, 27, 4063 (1994).

32. S. Valkama, H. Kosonen, J. Ruokolainen, T. Haatainen, M. Torkkeli, R. Serimaa, G. TenBrinke, and O. Ikkala, Nat. Mater. 872 (2004).

33. Y. W. Chiang, C. Y. Chou, C. S. Wu, E. L. Lin, J. Yoon, and E. L. Thomas, Macromolecules, 48, 4004 (2015).

34. Y. M. Chang, J. Shieh, and J. Y. Juang, J. Phys. Chem. C, 115, 8983 (2011).

35. J. W. Leem, Y. M. Song, and J. S. Yu, Opt. Exp., 19, 26308 (2011).

36. J. W. Leem, M. S. Kim, and J. S. Yu, J. Opt. Soc. Am. B, 30, 1665 (2013).

37. Opt. Exp. Volume 20, Pages 769-773 Superhydrophilic sapphires for high- performance optics J.W. Leem, J.S. Yu, Opt. Exp., 24, 26160 (2012).

38. A. Smyrnakis, E. Almpanis, V. Constantoudis, N. Papanikolaou, and E. Gogolides, Nanotechnology, 26(8), 085301 (2015).

39. Y-Y. Chou, K-T. Lee, and Y-C. Lee, Appl. Surf. Sci., 377, 81 (2016).

40. F. Teng, N. Li, L. Liu, D. Xu, D. Xiao, and N. Lu, RSC Adv., 6, 15803 (2016).

41. P. Mokarian-Tabari, R. Senthamaraikannan, C. Glynn, T. W. Collins, C. Cummins, D. Nugent, C. O'Dwyer, and M. A. Morris, Nano Lett., 17, 2973 (2017).

42. B. Paivanranta, P. K. Sahoo, E. Tocce, V. Auzelyte, Y. Ekinci, H. H. Solak, C.-C. Liu, K. O. Stuen, P. F. Nealey, and C. David, ACS Nano, 5, 1860 (2011).

43. A. Rahman, A. Ashraf, H. Xin, X. Tong, P. Sutter, M. D. Eisaman, and C. T. Black, Nat. Commun., 6, 5963 (2014).

44. T. Ghoshal, C. Ntaras, J. O'Connell, M. T. Shaw, J. D. Holmes, A. Avgeropoulos, and M. A. Morris, Nanoscale, 8, 2177 (2016).

45. J. Yang, F. Luo1, T.-S. Kao, X. Li, G.-W. Ho, J. Teng, X. Luo, and M. Hong, Light: Science \& Applications, 3, 185 (2014).

46. D. Borah, C. Cummins, S. Rasappa, S. M. Watson, A. R. Pike, B. R. Horrocks, D. A. Fulton, A. Houlton, G. Liontos, K. Ntetsikas, A. Avgeropoulos, and M. A. Morris, Nanotechnology, 28, 044001 (2017).

47. R. Ruiz, H. Kang, F. A. Detcheverry, E. Dobisz, D. S. Kercher, T. R. Albrecht, J. J. de Pablo, and P. F. Nealey, Science., 321, 936 (2008).

48. E. Han, K. O. Stuen, Y.-H. La, P. F. Nealey, and P. Gopalan, Macromolecules, 41, 9090 (2008).

49. E. W. Cochran, C. J. Garcia-Cervera, and G. H. Fredrickson, Macromolecules, 39, 2449 (2006).

50. N. L. J. Albert and T. H. Epps, III, MaterialsToday, 13, 24 (2010).

51. P. W. Majewski and K. G. Yager, Soft Matter, 12, 281 (2016).

52. H. Tada, Y. Yoshida, T. Ishida, J. K. Hirai, E. Bosworth, R. Dobisz, M. Ruiz, T. Takenaka, H. Hayakawa, and H. Hasegawa, Macromolecules, 45, 292 (2012).

53. K. W. Gotrik and C. A. Ross, Nano Lett. 13, 5117 (2013).

54. P. Mokarian-Tabari, C. Cummins, S. Rasappa, C. Simao, C. M. S. Torres, J. D. Holmes, and M. A. Morris, Langmuir, 30, 10728 (2014).

55. D. Borah, R. Senthamaraikannan, S. Rasappa, B. Kosmala, J. D. Holmes, and M. A. Morris, ACS Nano, 8, 6583 (2013).

56. K. D. Zhang, Harris, N. L. Y. Wu, J. N. Murphy, and J. M. Buriak, ACS Nano, 4, 7021 (2010).

57. E. W. Edwards, M. F. Montague, H. H. Solak, C. J. Hawker, and P. F. Nealey, Adv. Mater., 16, 1315 (2004).

58. J. Chai and J. M. Buriak, ACS Nano, 2, 489 (2008).

59. T. Xu, Y. Zhu, S. P. Gido, and T. P. Russell, Macromolecules, 37, 2625 (2004).

60. D. E. Angelescu, J. H. Waller, D. H. Adamson, P. Deshpande, S. Y. Chou, R. A. Register, and P. M. Chaikin, Adv. Mater, 16, 1736 (2004).

61. T. H. Epps III, Macromolecules, 46, 7567 (2013).

62. I. W. Hamley, Prog. Polym. Sci., 34, 1161 (2009).

63. M. Stefik, S. Guldin, S. Vignolini, U. Wiesnerd, and U. Steiner, Chem. Soc. Rev., 44, 5076 (2015).

64. S. Rasappa, H. Hulkkonen, L. Schulte, S. Ndoni, J. Reuna, T. Salminen, and T. Niemi, J. Colloid Interf. Sci., 534, 420 (2019).

65. A. C. Liapis, A. Rahman, and C. T. Black, Appl. Phys. Lett., 111, 183901 (2017).

66. C. Sinturel, M. Vayer, M. A. Morris, and M. A. Hillmyer, Macromolecules, 46, 5399 (2013).

67. S. H. Mir and B. Ochiai, Macromol. Mater. Eng., 301, 1026 (2016).

68. S. H. Mir and B. Ochiai, Adv. Mater. Interfaces, 4, 1601198 (2017).

69. S. H. Mir and B. Ochiai, J. Electrochem. Soc., 165 (8) B3030 (2018). 